\title{
EFFECT OF ANTIOXIDANT TREATMENT AND DELAYED BONDING ON SHEAR BOND STRENGTH OF PORCELAIN LAMINATE VENEERS BONDED TO BLEACHED ENAMEL (IN VITRO STUDY)

\author{
Beltagui $\mathrm{S}^{1} B D S$, Bakry $\mathrm{S}^{2} P h D$, Hussein $\mathrm{S}^{2} P h D$, Mohy El Din $\mathrm{M}^{3} P h D$
}

\begin{abstract}
:
Introduction: Porcelain laminate veneers are sometimes necessary after bleaching in patients requiring marked change in tooth color. Bonding following bleaching has been shown to be compromised. The use of an antioxidant agent and delayed bonding could improve bonding.

Aim of the study: was to evaluate the effect of antioxidant treatment and delayed bonding, one week after bleaching, on the shear bond strength of porcelain laminate veneers bonded to bleached enamel in comparison with immediate bonding after bleaching.

Materials and methods: Forty freshly extracted maxillary central incisors with flat enamel surfaces were prepared and divided into four groups ( $\mathrm{n}=10$ /group). Three test groups were bleached with $40 \%$ hydrogen peroxide (Power Whitening) and one control group was left as unbleached enamel. Forty glass ceramic discs were fabricated using IPS e.max Press to be bonded to the enamel surface. Group A:antioxidant treated specimens. Bleached specimens were treated with an antioxidant agent, 10\% sodium ascorbate, for 10 minutes then glass ceramic discs were bonded to the specimens. Group B:delayed bonded specimens. Bleached specimens were stored in artificial saliva for 7 days then glass ceramic discs were bonded to the specimens. Group C: immediate bonded specimens. Glass ceramic discs were immediately bonded to bleached specimens. Group D:control group. Glass ceramic discs were bonded to unbleached specimens. Dual cured resin cement (RelyX U200) was used for bonding. Following bonding, the specimens were thermocycled for 600 cycles corresponding to one clinical year service then tested for shear bond strength using a universal testing machine at a crosshead speed of $0.5 \mathrm{~mm} / \mathrm{min}$. Bond failure analysis was evaluated for the specimens using a stereomicroscope and random samples were chosen to be tested under a scanning electron microscope.
\end{abstract}

Results: No significant difference was found between the control, delayed bonding and antioxidant treated group ( $\mathrm{p}<0.001)$. Immediately bonded group showed significantly lower mean bond strength with glass ceramic discs than all groups ( $\mathrm{p}<0.001)$.

Conclusions: It is recommended to delay bonding for one week after bleaching or use $10 \%$ sodium ascorbate to reverse bleaching.

Keywords: Antioxidant, delayed bonding, shear bond strength, bleaching.

1- Dentist, Faculty of Dentistry, Alexandria University, Egypt.

2- Professor, Fixed Prosthodontics, Faculty of Dentistry, Alexandria University, Egypt.

3- Professor, Dental Biomaterials, Faculty of Dentistry, Alexandria University, Egypt.

\section{INTRODUCTION}

Esthetics is now of prime importance in dentistry, since patients continue to demand the "perfect smile". Previous studies have shown that more than $21 \%$ of people are dissatisfied with their tooth color (1). Tooth discoloration differs in etiology, appearance, localization, severity, and adhesion to tooth structure. It can be defined as being extrinsic or intrinsic on the basis of localization and etiology (2).

Extrinsic discoloration is caused by dietary chromogens, smoking and other external elements such as coffee and tea. Intrinsic discoloration, on the other hand often results from systemic or pulpal origin; stains could also internalize through extrinsic stains entering the dentine via tooth cracks (3).

One of the methods available to manage discolored teeth is bleaching to camouflage the underlying discoloration as well as the use of veneers and crowns (4).

The use of hydrogen peroxide or peroxide releasing agents, such as carbamide peroxide or sodium perborate, for brightening discolored teeth, has become a popular treatment modality (5). Bleaching decreases the translucency of enamel, thus less light would fall on dentin and less light from dentin would be reflected to the human eye. As a result dentin color would pose less influence on the overall tooth color and the object would seem lighter (6).

At times, both bleaching procedures and coverage by laminate veneers is necessary. Studies have previously shown that a porcelain veneer's ability to mask discoloration is dependent upon its shade, thickness, the cement used and the underlying tooth color (7).

However, bonding of adhesively attached restorations to pre-bleached dental hard tissue has proved to be significantly reduced (5). This may be due to changes in enamel structure resulting from loss of mineral content, or increased porosity as manifested by an "over-etched" appearance with loss of prismatic form of the enamel (8).

Recent studies have shown improved adhesion with treatment of bleached enamel with antioxidant, and most studies have investigated bonding of composite restorations to bleached enamel. However, further investigations are still required to investigate the optimum technique to use for adhesion of porcelain to enamel following bleaching, especially when bonding is to be implemented immediately after bleaching.

This study evaluated the effect of antioxidant treatment and delayed bonding on the shear bond strength of porcelain laminate veneers bonded to bleached enamel. 


\section{MATERIALS AND METHODS}

Forty extracted maxillary central incisors were collected from the Oral Surgery Department at the Faculty of Dentistry, Alexandria University.

\section{Inclusion Criteria:}

- Permanent maxillary central incisors having intact labial enamel.

\section{Exclusion Criteria:}

- Deep carious tooth.

- Teeth with developmental disorders that affect enamel and/or dentine such amelogenesis imperfecta and dentinogenesis imperfecta.

- Hypoplasia, hypocalcification, caries on labial surface, history of application of previous chemical agents, and enamel fractures.

\section{Sample size \& grouping:}

Forty teeth were randomly assigned to four groups, each group consisted of ten. Those were as follows:

Group A: "Antioxidant treatment": ceramic specimens bonded to enamel surfaces that were treated with an antioxidant following bleaching.

Group B: "Delayed bonding": ceramic specimens bonded to enamel surfaces after immersion in artificial saliva for one week following bleaching.

Group C: "Immediate bonding": ceramic specimens bonded to enamel surfaces immediately after bleaching.

Group D: "Untreated enamel group": ceramic specimens bonded to unbleached and untreated enamel surfaces (control group).

\section{Preparation of teeth and fabrication of glass ceramic discs:}

The 40 teeth were cleaned of any residual tags, pumiced and washed under running tap water. The roots were separated from the crowns using a low speed diamond disc under constant water cooling at the cement-enamel junction.

The teeth were attached to acrylic blocks of self-cure acrylic resin that was placed in a rectangular split copper mold of $15 \mathrm{~mm}$ diameter and $1 \mathrm{~cm}$ depth. The labial surfaces were placed facing upwards with an incisal $2 / 3$ inclination. The labial surfaces were flattened using sandpaper disc at low speed under running water.

Forty lithium disilicate glass ceramic discs were fabricated from IPS e.max Press (IvoclarVivadent. Benderestrasse 29494 Schann, Liechtenstein, Switzerland) using a rectangular split mold by the lost wax technique. A Press furnace - Programat EP 3000 (IvoclarVivadent. Benderestrasse 29494 Schann, Liechtenstein, Switzerland) was used. The discs were standardized at $6 \mathrm{~mm}$ diameter and $4 \mathrm{~mm}$ height. A digital caliper was used to verify measurements.

\section{Technique}

\section{Group A (Antioxidant treatment)}

Specimens of this group were bleached using POWER
WHITENING YF gel (WHITEsmile GmbH. Weinheimer Straße 6, 69488 Birkenau, Germany). 1-2 mm thick layer of gel was applied on the surface of the teeth and left for 20 minutes. Then the gel was removed from the teeth by suction and rinsed with tap water. An antioxidant agent of $10 \%$ sodium ascorbate (Faculty of Pharmacy, Alexandria University, Egypt) was then applied to the specimens immediately following bleaching using a disposable brush. It was left for 10 minutes then rinsed with tap water for 40 seconds and dried with oil free compressed air.

The glass ceramic discs were then bonded to the treated enamel surfaces. The discs were etched using $5 \%$ hydrofluoric acid (IvoclarVivadent. Benderestrasse 29494 Schann, Liechtenstein, Switzerland) for 20 seconds then rinsed off under running water. Then an organic silane coupling agent, Monobond Plus (IvoclarVivadent. Benderestrasse 29494 Schann, Liechtenstein, Switzerland), was applied for 60 seconds. The discs were then air dried thoroughly with oil free compressed air.

RelyX U200 Automix syringe (3M ESPE. Dental Products. St. Paul, MN) was used to get a homogenous paste that was applied on the surface of the treated enamel surface and the treated glass ceramic disc. A specially designerd static load device (Designed by Dr. Azer A., Conservative Department, Faculty of Dentistry, Alexandria University) was used to apply standardized static weight of $2 \mathrm{~kg}$ (9) on the glass ceramic disc. A scaler was used to remove the excess after 2 seconds. Afterwards, it was cured for 40 seconds using a light curing (LED) unit (IvoclarVivadent. Benderestrasse 29494 Schann, Liechtenstein, Switzerland).

After bonding, the specimens were thermally cycled between $5-55^{\circ} \mathrm{C}$ temperatures for 600 thermal cycles (10) corresponding to one year of clinical service.

\section{Group B (Delayed bonding)}

Specimens of this group were bleached using WHITEsmile POWER WHITENING YF Gel as in group A. After bleaching, the specimens were placed in artificial saliva in a glass laboratory beaker for 7 days.

The artificial saliva solution was changed twice daily during the 7-day time period (11). After the specimens were removed from the artificial saliva, the enamel surfaces were rinsed with an air/water spray free of oil for 30 seconds.

Treated ceramic discs were then bonded to the bleached enamel specimens as in group A using RelyX U200. Afterwards the bonded specimens were thermocycled for 600 cycles corresponding to one year of clinical service as in group A.

\section{Group C (Immediate bonding):}

Specimens of this group were bleached using WHITEsmile POWER WHITENING YF Gel as in group A. Treated ceramic discs were then bonded to them using the same technique as in group A using RelyX U200 but immediately after bleaching. Afterwards the bonded specimens were thermocycled for 600 cycles corresponding to one year of clinical service as in group A 


\section{Group D (Control):}

Specimens of this group were not bleached. Treated ceramic discs were bonded to them as in group A using RelyX U200. Afterwards the bonded specimens were thermocycled for 600 cycles corresponding to one clinical year of clinical service as in group A.

\section{Testing:}

\section{1) Shear bond strength:}

After thermocycling of the specimens, all the 40 bonded specimens were tested for shear bond strength using a Universal Testing Machine (Comten Industries Inc., Florida, USA )(Fig. 1). The load of the universal testing machine was applied parallel to the long axis of the specimen's surface close to the bonded area, at a crosshead speed of $0.5 \mathrm{~mm} / \mathrm{min}$ until debonding of the ceramic disc occurred.

The load denoting failure point was then recorded. Shear bond strength (B) values was calculated using the following formula (12):

Where:

$$
\mathbf{B}=\mathbf{F} \times \mathbf{S}^{-1}
$$

B: Shear bond strength in MPa

F: the load in $\mathrm{N}$ at break

S: the bonded area of the cylinder in $\mathrm{mm}^{2}$ $\mathrm{S}=\pi \mathrm{r}^{2}$

Where:

S: the bonded area of the cylinder in $\mathrm{mm}^{2}$

$\pi: 3.14159$

$\mathbf{r}$ : radius of the cylinder in $\mathrm{mm}$

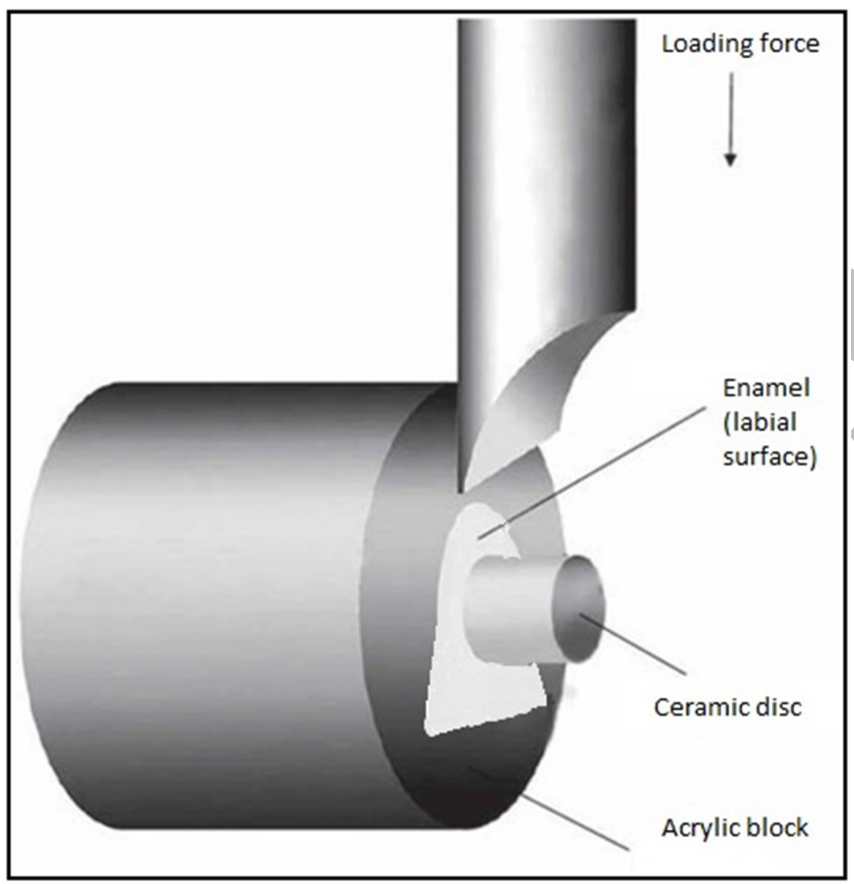

2) Mode of failure under stereomicroscope:

After the shear bond strength testing, all the specimens were observed using a stereomicroscope (Olympus SZ-CTV, Japan) and linked digital camera (Panasonic WV-CP 230/ G,
Japan) at $20 \times$ original magnification for assessement of the failure mode after bond failure.

\section{Type of failure:}

Adhesive: failure at the enamel-ceramic interface.

Cohesive: failure in the enamel alone or the ceramic alone.

Mixed: a combination of adhesive and cohesive failures.

\section{3) Scanning electron microscopy:}

To further demonstrate the modes of failures, two specimens (an adhesive failure and a cohesive failure one) were randomly selected to be scanned under the scanning electron microscope (JEOL JSM-5300, Japan). They were ultrasonically cleaned for 15 minutes to remove debris and dried. They were then sputter coated with gold and viewed under the microscope under several magnifications. Those were $\times 75, \times 1000, \times 3500$ and $\times 7500$.

\section{Statistical analysis:}

Data was collected and subjected to statistical analysis.

\section{RESULTS}

The results of this study revealed that the unbleached, control group (group D) showed the highest shear bond strength, followed by the delayed bonding group (group B), followed by the antioxidant treatment group (group A) and the lowest value for shear bond strength was the immediate bonding group (group C). Statistical analysis of shear bond strength results of the four studied groups is represented in table 1.

Table (1): Comparison between the different studied groups according to shear bond strength in $\mathrm{MPa}$.

\begin{tabular}{|c|c|c|c|c|c|c|}
\hline & $\begin{array}{c}\text { Antioxidant } \\
\text { treatment } \\
(\mathrm{n}=10)\end{array}$ & $\begin{array}{l}\text { Delayed } \\
\text { bonding } \\
(\mathrm{n}=10)\end{array}$ & $\begin{array}{c}\text { Immediate } \\
\text { b onding } \\
(\mathrm{n}=10)\end{array}$ & $\begin{array}{l}\text { Control } \\
(n=10)\end{array}$ & $\mathbf{F}$ & $\mathbf{P}$ \\
\hline Shear bond stre & & & & & \multirow{4}{*}{$392.607^{\circ}$} & \multirow{4}{*}{$<0.001^{\circ}$} \\
\hline Min. - Max & $14.31-17.51$ & $15.70-17.71$ & $5.48-7.97$ & $16.22-17.78$ & & \\
\hline Mean $=S D$ & $16.19=1.04$ & $16.85=0.76$ & $6.48=0.78$ & $17.03=0.63$ & & \\
\hline Median & 16.50 & 16.95 & 6.65 & 17.12 & & \\
\hline \multirow{2}{*}{$\begin{array}{c}\mathrm{P}_{\mathrm{Con}} \\
\mathbf{P}\end{array}$} & 0.114 & 0.962 & $<0.001^{\circ}$ & & & \\
\hline & \multicolumn{3}{|c|}{$p_{1}=0.277, p_{2}<0.001^{\circ}, p_{2}<0.001^{\circ}$} & & & \\
\hline
\end{tabular}

There was no significant difference between shear bond strength of the antioxidant treatment group (group A), delayed bonding (group B) and that of the control group (group D). The shear bond strength between the immediate bonding group (group C) and all other groups (groups A, B and D) was significantly lower.

The numbers, percentage and statistical analysis of different types of bonding failure for each group according to stereomicroscopic imaging are summarized in table 2 . There were no significant differences between all four groups. Almost all bonding failures were of the adhesive type. Only the control group (group D) showed cohesive failures within the tooth structure together with the adhesive failures.

Cohesive failure pattern appears on the debonded enamel specimen from Group D (control group). Enamel 
appears separated and fracture appears in the dentine (Fig. 2-3).

Adhesive failure is seen as adhesive resin appears on the enamel surface of the debonded specimen from Group A (antioxidant treatment) (Fig. 4-5).

Table (2): Comparison between the different studied groups according to failure mode.

\begin{tabular}{|c|c|c|c|c|c|c|c|c|c|c|}
\hline & \multicolumn{2}{|c|}{$\begin{array}{c}\text { Antioxidant } \\
\text { treatment } \\
(n=10)\end{array}$} & \multicolumn{2}{|c|}{$\begin{array}{l}\text { Delayed } \\
\text { bonding } \\
(\mathrm{n}=10)\end{array}$} & \multicolumn{2}{|c|}{$\begin{array}{c}\text { Immediate } \\
\text { bonding } \\
(\mathrm{n}=10)\end{array}$} & \multicolumn{2}{|c|}{$\begin{array}{l}\text { Control } \\
(n=10)\end{array}$} & \multirow[t]{2}{*}{$x^{2}$} & \multirow[t]{2}{*}{${ }^{M C_{p}}$} \\
\hline & No. & $\%$ & No. & $\%$ & No. & $\%$ & No. & $\%$ & & \\
\hline \multicolumn{11}{|l|}{ Failure mode } \\
\hline Adhesive & 10 & 100.0 & 10 & 100.0 & 10 & 100.0 & 8 & 80.0 & \multirow{3}{*}{3.811} & \multirow{3}{*}{0.235} \\
\hline Cohesive & 0 & 0.0 & 0 & 0.0 & 0 & 0.0 & 2 & 20.0 & & \\
\hline Mixed & 0 & 0.0 & 0 & 0.0 & 0 & 0.0 & 0 & 0.0 & & \\
\hline
\end{tabular}

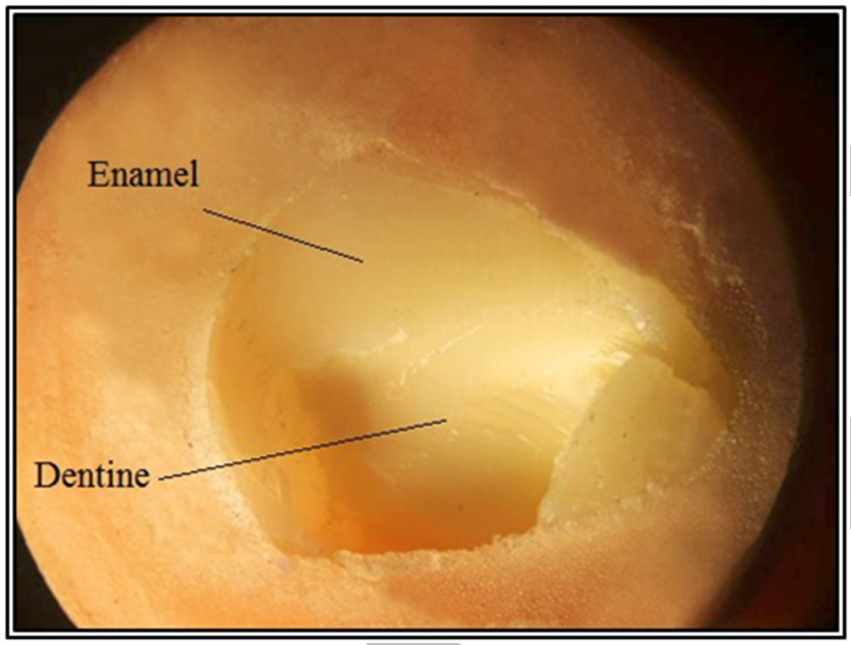

Fig. (2): Cohesive failure within the tooth structure in Group D (control group).

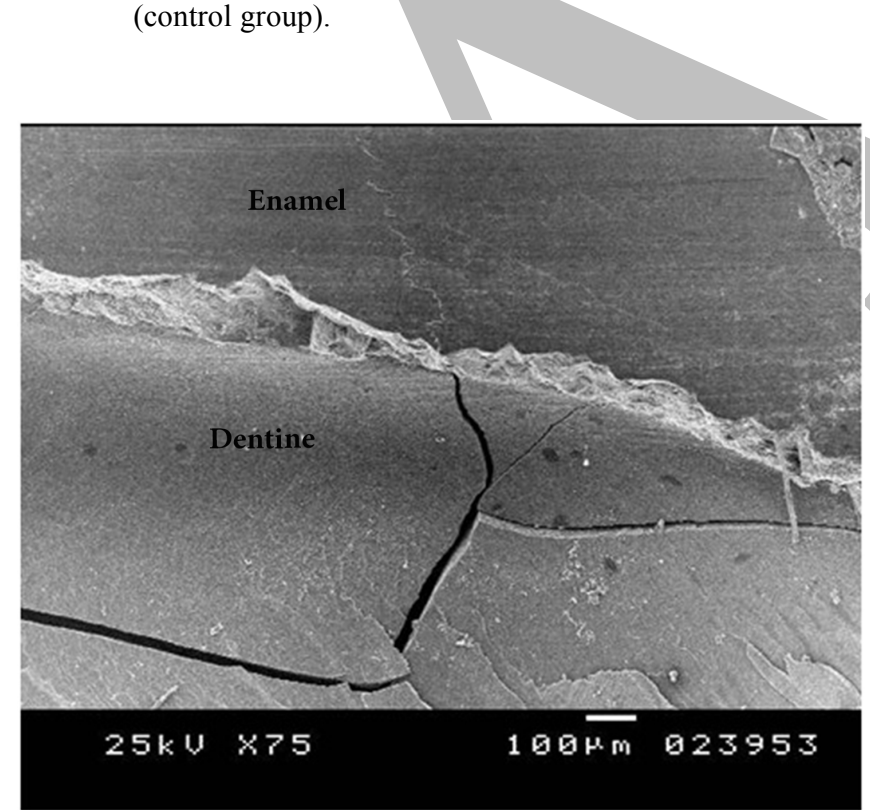

Fig. (3): Scanning electron micrograph $(\times 75)$ showing cohesive failure pattern on debonded enamel specimen from Group D (control group).

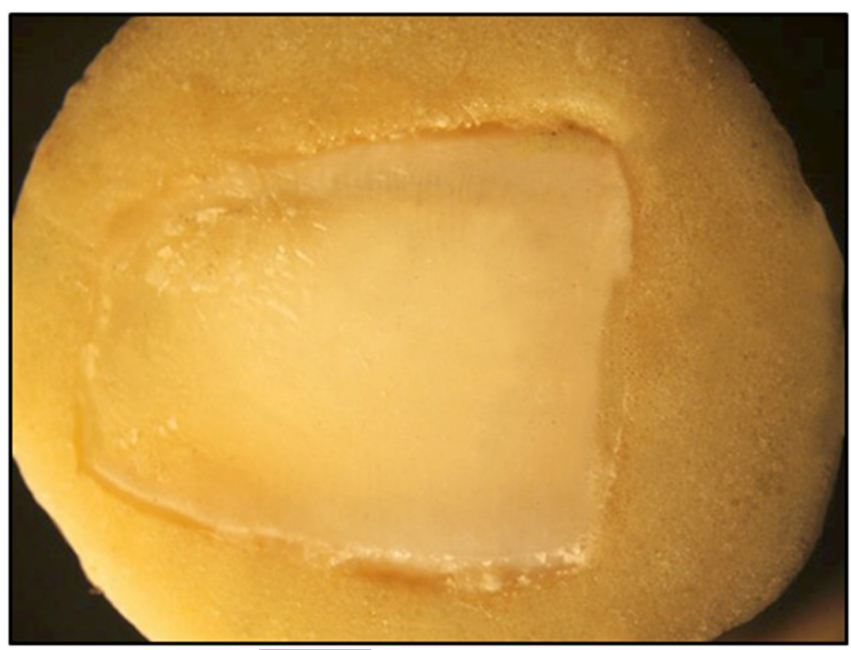

Fig. (4): Adhesive failure in Group A (antioxidant treatment).

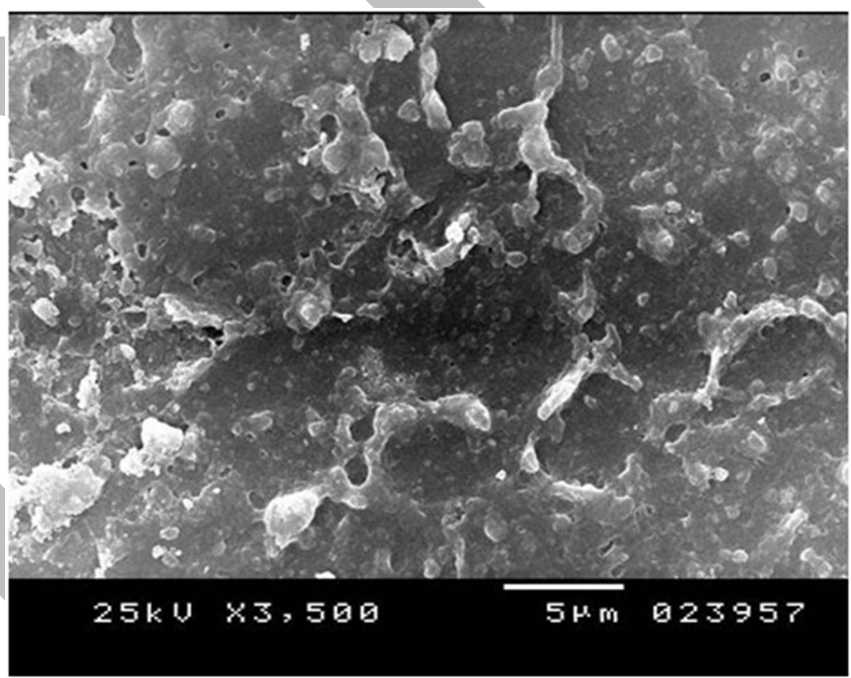

Fig. (5): Scanning electron micrograph $(\times 3500)$ showing the adhesive resin on the enamel surface of the debonded specimen from Group A (antioxidant treatment).

\section{DISCUSSION}

Following bleaching procedures, patients often require additional aesthetic interventions such as, replacement of old restorations or application of laminate veneers to restore aesthetic deficiencies. However, a number of studies $(13,14)$ have shown that the bond strengths of adhesive restorations to tooth structures are reduced when the tooth has been bleached. Thus, the initial decrease in enamel bond strength after bleaching is clinically important.

The need for immediate bonding after bleaching especially for patients with hectic schedules and the lack of sufficient studies on the best method to treat reduced bond strength following bleaching were the motivating factors of this study.

Most studies (15-17) have investigated bonding of composites after bleaching using different self etch or total 
etch cements. Bonding after bleaching with different concentrations of sodium ascorbate, an antioxidant, has been usually compared to delayed bonding after a week or two weeks. Bleaching has been investigated using several concentrations of carbamide peroxide or hydrogen peroxide.

Accordingly, the present study was designed to evaluate the effect of antioxidant treatment and delayed bonding on the shear bond strength of porcelain laminate veneers bonded to bleached enamel in comparison with those immediately bonded after bleaching.

An antioxidant agent was tested to investigate an alternative to delayed bonding after bleaching. Among all methods, the antioxidant treatment using sodium ascorbate has shown immediate improvement. Sodium ascorbate may be used in the form of solution or gel in different concentrations as 2.5, 5, 10 and $20 \%$. The gel form of sodium ascorbate was used in this study; for ease of application owing to its higher viscosity and better control. It was applied in the concentration of $10 \%$ for 10 minutes, which is a reasonable time period for clinical application (18). It was used in the concentration of $10 \%$ as concentrations lower than that may not be as reliable in reversing compromised bond strength (19); and higher as $20 \%$ has been shown to yield similar results as $10 \%(20)$.

Although there are remarkable variations among the recommended post bleaching time periods in different studies, most researchers advised delays in bonding of 1 week after bleaching. It has been expected that under clinical conditions, saliva may have similar action after bleaching. Therefore, the delayed bonding group in this study was immersed in artificial saliva for 1 week (14).

The results of this study showed that the shear bond strength of the three groups, antioxidant treatment, control and delayed bonding (groups A, B and D) were much higher than the immediate bonding group (group $\mathrm{C}$ ), with the control being the highest.

These results were in agreement with Turkun et al. in 2004 (18) who reported that there were no statistically significant differences in respect to shear bond strength between the antioxidant-treated group, the delayed bonding group and the control group. However, it was found that shear bond strength of the immediately bonded group was significantly lower than that of all other groups despite using different concentrations of carbamide peroxide as a bleaching agent.

The results were also in agreement with those of Danesh-Sani et al. in 2011 (14) who used hydrogen peroxide as a bleaching agent instead of carbamide peroxide and found that there was no significant difference between the control group, the delayed bonding group and the antioxidant-treated group. Nevertheless, immediately bonding after bleaching with hydrogen peroxide demonstrated significantly lower shear bond strength.

The shear bond strength results of delayed bonding group support previous investigations that stated that immersion of the specimens in artificial saliva or distilled water for one week resulted in complete reversal of the enamel bond reduction $(14,21)$. This may be due to removal of residual oxygen from the bleaching material by the immersion process. It has been expected that oral cavity saliva may have similar action after bleaching (14).

Nevertheless, the results of the present study regarding delayed bonding disagree with those of Borges et al. in 2007 (22), who found that it takes 3 weeks for bond strength values of enamel to return to normal following bleaching. This may be due to different types of resin cements being used as well as different bleaching agents that were left for longer periods of time than during this study.

In this present study, the use of antioxidants before bonding has shown to increase the shear bond strength. Results are also in agreement with the results of Lai et al. in 2002 (23) who tested immediate bonding and bonding after antioxidant treatment to find that compromised bonding to acid-etched bleached enamel was reversed with sodium ascorbate, an antioxidant.

Previous studies (24) suggested that the subsurface enamel organic matrix is altered by the oxidizing effect of hydrogen peroxide. Based on our present findings, it is possible that these are not permanent structural alterations, but reversible changes in redox potential of the organic components. It is also speculated that the peroxide ions may have temporarily substituted the hydroxyl radicals in the appatite lattic (25). Since these lattice substitutions are thermodynamically unfavorable, such a process may be reversed by an antioxidant. Ascorbic acid and its salts are well known antioxidants and are capable of reducing a variety of oxidative compounds, especially free radicals.

With regards to antioxidant application, the results of the present study are in disagreement with Torres et al. in 2006 (26) who concluded that no significant difference in bond strength was observed between antioxidant treated enamel surface after bleaching and immediately bonded bleached enamel surface. Moreover, no significant difference was found between the bond strength of the antioxidant treated group and the control group. This could be due to different types of resin cements used. This study also used a solution of sodium ascorbate instead of a gel.

In previous studies, the most common failure modes for self-adhesive cements have been adhesive and mixed failures, with only a small percentage comprising true cohesive failures (27). The failure mode is largely influenced by the test mechanics and material properties. In 
this study, failures were mainly adhesive in nature and occurred at the resin/tooth interface, consistent with the findings of other studies $(28,29)$. These observations support the conclusion that self-adhesive cements interact only superficially, with little infiltration in the tooth.

\section{CONCLUSIONS}

Within the limitations of this study, the following conclusions could be drawn:

1) Bleaching enamel reduces shear bond strength.

2) One week delayed bonding after bleaching retores the reduced bond strength.

3) Treatment of the bleached enamel surfaces with $10 \%$ sodium ascorbate for 10 minutes restores the reduced bond strength and may be an alternative to delayed bonding.

\section{CONFLICT OF INTEREST}

The authors declare that they have no conflicts of interest.

\section{REFERENCES}

1. Griffiths CE, Bailey JR, Jarad FD, Youngson CC. An investigation into most effective method of treating stained teeth: An in vitro study. J Dent. 2008; 36: 54 62.

2. Plotino G, Buono L, Grande NM, Pameijer CH, Somma F. Nonvital tooth bleaching: a review of the literature and clinical procedures. J Endod. 2008; 34: 394-407.

3. Sulieman M. An overview of tooth discoloration: extrinsic, intrinsic and internalized stains. Dent Update. 2005; 32: 463-71.

4. Sulieman M, Addy M, Rees J. Development and evaluation of a method in vitro to study the effectiveness of tooth bleaching. J Dent. 2003; 31: 41522.

5. Attin T, Hannig C, Wiegand A, Attin R. Effect of bleaching on restorative materials and restorations - A systematic review. Dent Mater. 2004; 20: 852-61.

6. Ma X, Li R, Sa Y, Liang S, Sun L, Jiang T, et al. Separate contribution of enamel and dentine to overall tooth colour change in tooth bleaching. J Dent. 2011; 39: 739-45.

7. Jarad FD, Griffiths CE, Jaffri M, Adeyemi AA, Youngson CC. The effect of bleaching, varying the shade or thickness of composite veneers on final colour: An in vitro study. J Dent. 2008; 36: 554-9.

8. Sung EC, Chan SM, Mito R, Caputo AA. Effect of carbamide peroxide bleaching on the shear bond strength of composite to dental bonding agent enhanced enamel. J Prosthet Dent. 1999; 82: 595-9.

9. Tashkandi E. Effect of surface treatment on the micro- shear bond strength to zirconia. Saudi Dent J. King Saud University; 2009; 21: 113-6.

10. Krejci I, Lutz F, Reimer M. Marginal adaptation and fit of adhesive ceramic inlays. J Dent. 1993; 21: 39-46.

11. Gökçe B, Çömlekoğlu ME, Özpinar B, Türkün M, Kaya AD. Effect of antioxidant treatment on bond strength of a luting resin to bleached enamel. J Dent. 2008; 36: 780-5.

12. Rüttermann S, Braun A, Janda R. Shear Bond Strength and Fracture Analysis of Human vs. Bovine Teeth. PLoS One. 2013; 8.

13. Silva JMG da, Botta AC, Barcellos DC, Pagani C, Torres CRG. Effect of antioxidant agents on bond strength of composite to bleached enamel with $38 \%$ hydrogen peroxide. Mater Res. Materials Research; 2011; 14: 235-8.

14. Danesh-Sani S, Esmaili M. Effect of $10 \%$ sodium ascorbate hydrogel and delayed bonding on shear bond strength of composite resin and resin-modified glass ionomer to bleached enamel. J Conserv Dent. 2011; 14: 241.

15. García-Godoy F, Dodge WW, Donohue M, O'Quinn JA. Composite resin bond strength after enamel bleaching. Oper Dent. 18: 144-7.

16. Kaya AD, Türkün M, Arici M. Reversal of compromised bonding in bleached enamel using antioxidant gel. Oper Dent. 33: 441-7.

17. Titley KC, Torneck CD, Smith DC CR, Microscopy AA. Scanning electron microscopy observations on the penetration and structure on the resin tags in bleached and unbleached bovine enamel. J Endodont. 1991; 17: $72-5$.

18. Türkün M, Kaya AD. Effect of $10 \%$ sodium ascorbate on the shear bond strength of composite resin to bleached bovine enamel. J Oral Rehabil. 2004; 31: 1184-91.

19. Türkün M, Celik EU, Kaya AD, Arici M. Can the hydrogel form of sodium ascorbate be used to reverse compromised bond strength after bleaching? J Adhes Dent. 2009; 11: 35-40.

20. Kimyai S, Valizadeh H. The effect of hydrogel and solution of sodium ascorbate on bond strength in bleached enamel. Oper Dent. Operative Dentistry, Inc; 2006; 31: 496-9.

21. Unlu N, Cobankara FK, Ozer F. Effect of elapsed time following bleaching on the shear bond strength of composite resin to enamel. J Biomed Mater Res B Appl Biomater. 2008; 84: 363-8.

22. Borges AB, Rodrigues JR M AL. The influence of bleaching agents on enamel bond strength of a composite resin according to the storage time. Rev 
Odontol. 2007; 36: 77-83.

23. Lai SCN, Tay FR, Cheung GSP, Mak YF, Carvalho RM, Wei SHY, et al. Reversal of compromised bonding in bleached enamel. J Dent Res. 2002; 81: 477-81.

24. Hegedüs C, Bistey T, Flóra-Nagy E, Keszthelyi G, Jenei A. An atomic force microscopy study on the effect of bleaching agents on enamel surface. J Dent. 1999; 27: 509-15.

25. Zhao H, Li X, Wang J, Qu S, Weng J, Zhang X. Characterization of peroxide ions in hydroxyapatite lattice. J Biomed Mater Res. 2000; 52: 157-63.

26. Torres CRG, Borges AFK\& AB. The effects of antioxidant agents as neutralizers of bleaching agents on enamel bond strength. Brazilian J Oral Sci. Piracicaba Dental School - UNICAMP; 5: 971-6.

27. Braga RR, Meira JBC, Boaro LCC, Xavier TA. Adhesion to tooth structure: A critical review of "macro" test methods. Dent Mater. 2010; 26: 38-49.

28. Lin J, Shinya A, Gomi H, Shinya A. Effect of selfadhesive resin cement and tribochemical treatment on bond strength to zirconia. Int J Oral Sci. 2010; 2: 2834.

29. Viotti RG, Kasaz A, Pena CE, Alexandre RS, Arrais $\mathrm{CA}$, Reis AF. Microtensile bond strength of new selfadhesive luting agents and conventional multistep systems. J Prosthet Dent. 2009; 102: 306-12.

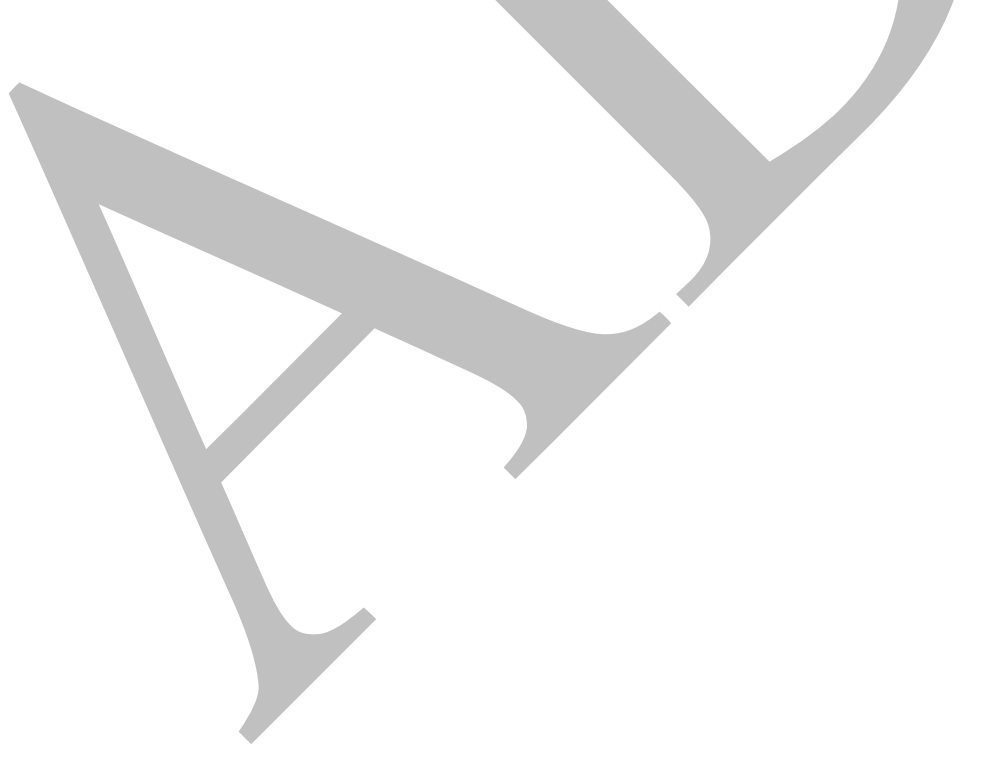

